\title{
Estimation of Glomerular Filtration Rate from Plasma Clearance of 51-Chromium Edetic Acid
}

\author{
C. CHANTLER $\star$ and T. M. BARRATT \\ From the Department of Immunology, Institute of Child Health, 30 Guilford Street, and Guy's Hospital, London
}

\begin{abstract}
Chantler, C., and Barratt. T. M. (1972). Archives of Disease in Childhood, 47, 613. Estimation of glomerular filtration rate from plasma clearance of 51-chromium edetic acid. The glomerular filtration rate was estimated by a single compartment analysis of the rate of fall of plasma concentration of 51-chromium edetic acid after a single intravenous injection. This slope clearance consistently overestimated the simultaneously determined standard urinary clearance, but could be used to predict the latter with an accuracy of $\pm 9 \%$ (95\% confidence limits). The coefficient of variation of replicate estimates of the slope clearance in the same individual was $3.9 \%$; thus two estimates of glomerular filtration rate by this technique which differ by $11 \%$ have a $95 \%$ probability of reflecting a genuine difference.

The method requires an intravenous injection and blood samples at 2 and 4 hours; urine samples are not required. It is simple, safe, and precise, and is applicable to children.
\end{abstract}

The estimation of glomerular filtration rate (GFR) is essential in the management of renal disease, but the inulin clearance is too complex and the endogenous creatinine clearance (Dodge, Travis, and Daeschner, 1967; Doolan, Alpen, and Theil, 1962; Kim et al., 1969) too imprecise for many clinical situations. There has therefore been a revival of interest in the possibility of estimating GFR from the rate of fall of plasma concentration of a substance after a single intravenous injection (slope clearance; C-slope) in spite of theoretical objections (Smith, 1951). The technique is so attractively simple that we have reexamined it using ${ }^{51}$ chromium edetic acid ${ }^{51} \mathrm{Cr}-$ EDTA) which is not metabolized and is excreted solely by the kidney; its clearance is about $5 \%$ less than the simultaneously determined inulin clearance (Chantler et al., 1969; Lavender, Hilton, and Jones, 1969; Stamp, Stacey, and Rose, 1970). Some results of the slope clearance technique have already been published (Chantler et al., 1969) which correlated closely with the urinary clearance measured by the standard clearance techniques (UV/P clearance; C-UV/P). The purpose of this

Received 13 December 1971.

*Present address: University of California, Department of Pediatrics, San Francisco General Hospital, Portrero Avenue, California 94110, U.S.A. paper is to extend these observations, and to investigate the reproducibility of the slope clearance and its applicability to children.

\section{Methods}

${ }^{51} \mathrm{Cr}-\mathrm{EDTA}$ * was diluted with $5 \%$ dextrose and $0.5-$ $1.0 \mu \mathrm{Ci} / \mathrm{kg}$ body weight was administered by intravenous injection in a volume of approximately $10 \mathrm{ml}$. The exact dose was' determined by weighing the syringe. A moderate diuresis was initiated with an oral water load and maintained throughout the test. Urine samples were obtained by voiding at 30-minute intervals and four venous blood samples were taken between 2 and 4 hours after the injection.

A dilution of the injected solution was used as reference standard and was counted with plasma and urine to an accuracy of $\pm 2 \%$. The urinary clearance (C-UV/P) was calculated from the urine activity, flow rate, and the interpolated plasma activity at the midpoint of each collection period with an allowance of 4 minutes for the mean renal transit time (Ekins et al., 1966). In all cases the plasma activity was apparently falling exponentially during the collection periods. C-UV/P was taken as the mean of the clearances obtained from each collection period.

The logarithm of the plasma activity $\left(\mathbf{P}_{\mathrm{t}}, \mathrm{cpm} / \mathrm{ml}\right)$ was plotted as a function of time and the apparent zero time plasma activity $\left(\mathbf{P}_{\mathrm{o}}\right)$ determined by extrapolation

«The Radiochemical Centre, Amersham, Bucks., England. Specific activity $700-1000 \mu \mathrm{Ci} / \mathrm{mg} \mathrm{Cr}$. 


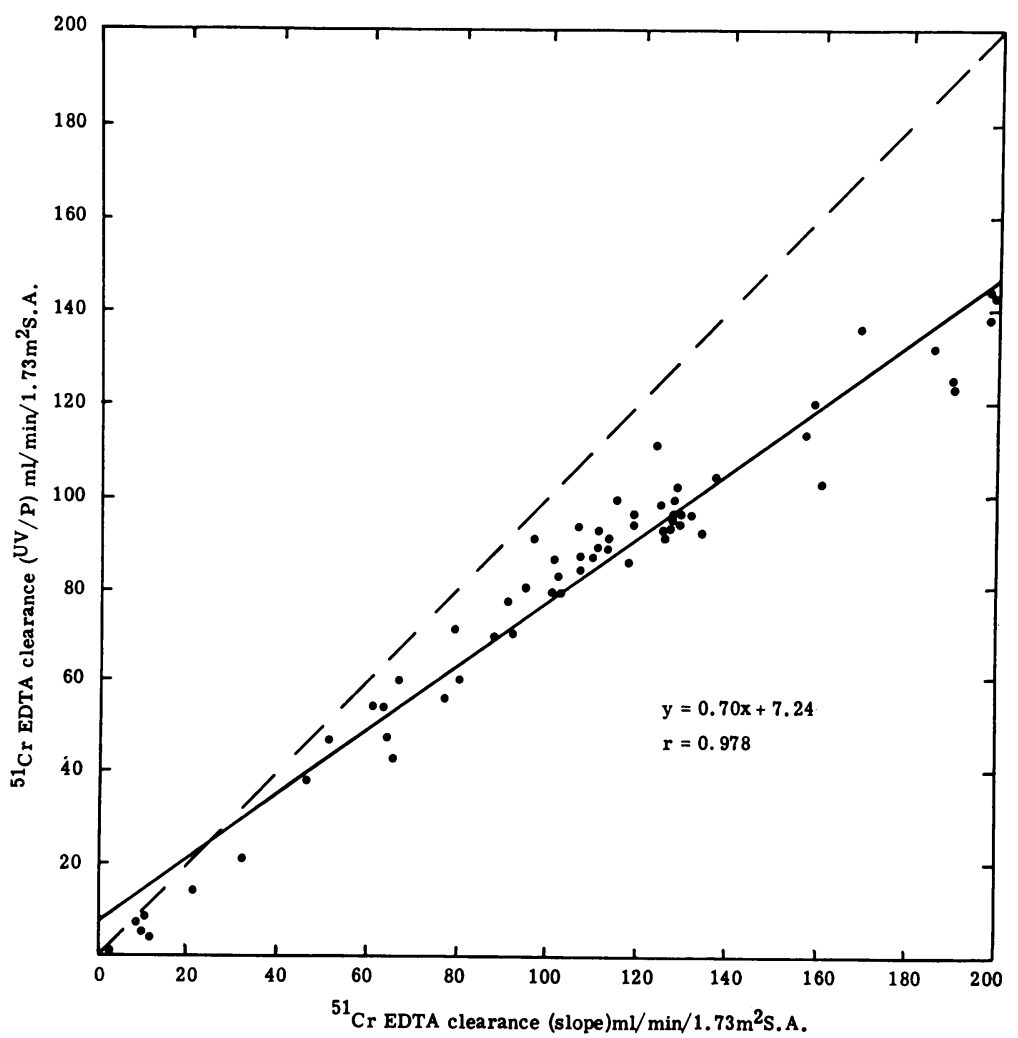

FIG. 1.-Relation between the simultaneously determined slope clearance and UVP clearance of ${ }^{51} \mathrm{Cr}-E D T A$.

of the linear part of the curve. The apparent volume of distribution $\left(\mathrm{V}_{\mathrm{p}}, \mathrm{ml}\right)$ was then derived:

Volume injected $(\mathrm{ml}) \times$ standard activity

$\mathrm{V}_{\mathrm{D}}=$ $(\mathrm{cpm} / \mathrm{ml}) \times$ dilution of standard

The half period $\left(T_{i}, \min \right)$ of the linear part of the plasma decay was determined from the graph and the slope clearance (C-slope, $\mathrm{ml} / \mathrm{min}$ ) calculated as :

$$
\text { C-slope }=\frac{0.693}{T_{t}} \times V_{D}
$$

For endogenous creatinine clearances (C-creat) the plasma creatinine was estimated after absorption into an ion exchange resin and elution with alkaline picrate (Stoten, 1968); urine creatinine was measured on an Autoanalyser (Technicon method N11b). All clearance values have been corrected to $1.73 \mathrm{~m}^{2}$ body surface area $(\mathrm{SA})$.

\section{Results}

Sixty-six simultaneous measurements of slope and UV/P clearance were obtained in healthy adult males and a group of non-oedematous adults and children over 5 years of age with a variety of renal diseases. The relation of C-slope to $\mathrm{C}-\mathrm{UV} / \mathrm{P}$ is shown in Fig. 1. The regression equation is: $\mathrm{C}-\mathrm{UV} / \mathrm{P}=0.70 \mathrm{C}$-slope $+7 \cdot 2(\mathrm{r}=0.98 ; \mathrm{n}=66)$. The mean ratio $(\mathrm{R})$ of $\mathrm{C}-\mathrm{UV} / \mathrm{P}$ to $\mathrm{C}$-slope for the ? 61 patients who had UV/P clearances of more than $10 \mathrm{ml} / \mathrm{min}$ per $1.73 \mathrm{~m}^{2} \mathrm{SA}$ was $0.77 \pm 0.07$ (SD) and the predicted UV/P clearance (C-slope $\times$ 0.77 ) expressed as a percentage of the observed $\mathrm{UV} / \mathrm{P}$ clearance had a SD of $9 \%$; this variation must in part be due to errors of estimation of the $D$ UV/P clearance. Inspection of Fig. 1 suggests that the relation between $\mathrm{C}-\mathrm{UV} / \mathrm{P}$ and C-slope is $\mathrm{N}$ not linear: the mean value of $R$ was significantly less in individuals in whom C-slope was less than $50 \mathrm{ml} / \mathrm{min}$ per $1.73 \mathrm{~m}^{2} \mathrm{SA}(\mathrm{R}=0.65)$ and greater $\mathrm{\omega}$ than $150 \mathrm{ml} / \mathrm{min}$ per $1.73 \mathrm{~m}^{2} \mathrm{SA}(\mathbf{R}=0 \cdot 70)$ than in those in whom C-slope was between 50 and 1500 $\mathrm{ml} / \mathrm{min}$ per $1.73 \mathrm{~m}^{2} \mathrm{SA}(\mathrm{R}=0 \cdot 79)$. There is also a slight but significant tendency for $\mathrm{R}$ to be lower in smaller individuals in the range of surface area studied $\left(0 \cdot 8-2 \cdot 2 \mathrm{~m}^{2}\right)$ :

$$
R=0.052 S A+0.69(r=0.32 ; n=61) \text {. }
$$


The validity of capillary blood sampling for determination of C-slope was investigated in 10 individuals in whom both capillary and venous samples were collected: the capillary C-slope was $101 \cdot 9 \% \pm 3.0 \%$ (SD) of the simultaneously determined venous C-slope.

The number of blood samples required for the accurate measurement of $\mathrm{C}$-slope was investigated in 99 consecutive clearance determinations for which the linear part of the curve had been identified with 4 blood samples, and the clearance recalculated using the plasma values at 2 and 4 hours only. In 63 instances the plasma specimens were collected by venepuncture and the 2 sample estimate of C-slope was $99 \cdot 7 \% \pm 1 \cdot 2 \%$ (SD) of the 4 sample estimate; in 36 clearances calculated from capillary samples (finger- or heel-prick) the corresponding figures were $99 \cdot 9 \% \pm 1.0 \%$ (SD).

The reproducibility of C-slope determinations in the same individual over a period of time was compared with that of the 24-hour endogenous creatinine clearance. Repeated measurements of C-slope were made over one year in 5 healthy adult males. The tests were performed between 9 a.m. and 1 p.m. after a normal breakfast, and whenever possible the subject was at rest during the last two hours of the test. Fluid intake varied; on some occasions a diuresis was initiated while on others water intake was governed by thirst. In the same individuals repeated estimates of creatinine clearances were obtained.

The results are shown in Tables I and II. The means and coefficients of variation of the observations on each individual are given. The pooled coefficient of variation of C-slope was $3.9 \%$; thus two estimates of GFR by the slope technique which differ by more than $11 \%$ have a $95 \%$ probability of reflecting a genuine difference. The

TABLE I

Replicate Estimates of GFR (ml/min) From Slope Clearance of ${ }^{51} \mathrm{Cr}-\mathrm{EDTA}$ in Healthy Adults

\begin{tabular}{l|c|c|c|c|c}
\hline \multicolumn{1}{c|}{ Individual } & CC & TMB & JFS & MS & JH \\
\hline & 133 & 135 & 143 & 128 & 118 \\
& 128 & 144 & 133 & 135 & 115 \\
& 127 & 146 & 151 & 134 & 122 \\
& 138 & 143 & 131 & 131 & 114 \\
& 130 & & & & \\
& 128 & & & & \\
& 137 & & & & \\
\hline Mean & 135 & & & & \\
Coefficient of variation & $3.2 \%$ & $3.4 \%$ & $6 \cdot 7 \%$ & $2 \cdot 4 \%$ & $3 \cdot 1 \%$ \\
\hline
\end{tabular}

Note: Pooled coefficient of variation $=3 \cdot 9 \%$. pooled coefficient of variation of creatinine clearance was $11 \cdot 6 \%$ : two estimates would have to differ by $30 \%$ for the change to be significant.

TABLE II

Replicate Measurements of Creatinine Clearance (ml/min) in Healthy Adults

\begin{tabular}{l|l|l|l|l|l}
\hline \multicolumn{1}{c|}{ Individual } & CC & TMB & JFS & MS & JH \\
\hline & 129 & 134 & 166 & 131 & 115 \\
& 160 & 128 & 136 & 129 & 125 \\
& 114 & 139 & 152 & 153 & 141 \\
& 150 & 110 & 157 & 171 & 116 \\
\hline Mean & 138 & 128 & 153 & 146 & 124 \\
Coefficient of variation & $15 \%$ & $9 \cdot 9 \%$ & $8 \cdot 2 \%$ & $14 \%$ & $9 \cdot 6 \%$ \\
\hline
\end{tabular}

Note: Pooled coefficient of variation $=11 \cdot 6 \%$.

\section{Discussion}

There are several ways of analysing the falling plasma concentration curve to estimate clearance. The single exponential analysis used in this study has the advantage that only the latter part of the curve need be identified and fewer blood samples are necessary-indeed two blood samples (venous or capillary) suffice, making the technique particularly suitable for children. The use of capillary samples is of particular advantage in infants, as is the elimination of the need for timed urine collection. Indeed, this technique is the only satisfactory means of estimating GFR in infants with obstructive uropathy (Barratt and Chantler, 1970).

Though C-slope overestimates C-UV/P and the ratio C-UV/P: C-slope shows slight but systematic variation, being lower in the extreme ranges of GFR and in smaller individuals, an empirical correction factor of 0.77 can be applied to the slope clearances greater than $10 \mathrm{ml} / \mathrm{min}$ per $1.73 \mathrm{~m}^{2} \mathrm{SA}$ to obtain a reasonably accurate estimate of the UV/P clearance with $95 \%$ confidence limits of $\pm 18 \%$. The UV/P clearance of ${ }^{51} \mathrm{Cr}-\mathrm{EDTA}$ is about $5 \%$ less than that of inulin (Chantler et al., 1969); also, if an allowance of about $10 \%$ is made for the arteriovenous concentration difference which exists when the plasma concentration is falling, a composite correction factor of 0.87 applied to the slope clearance provides a reasonable estimate of the GFR. This use of an empirical correction factor is at least as accurate as more complicated analytical treatments of the falling plasma concentration curve (Truniger, Donath, and Kappeler, 1968; Bröchner-Mortensen, Giese, and Rossing, 1969; Brien, O'Hagan, and Muldowney, 1969).

The presence of oedema may delay the equilibration of the tracer within its volume of distribution 


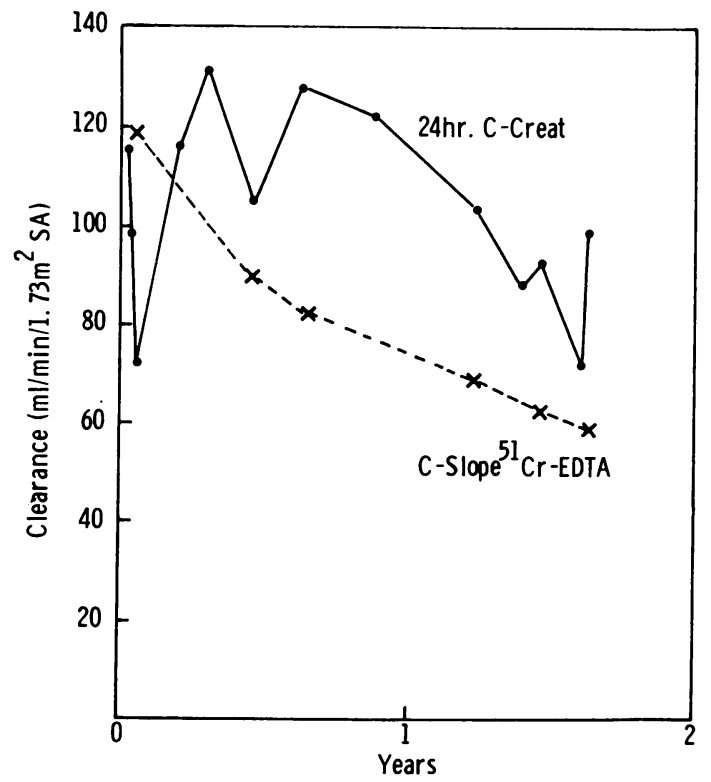

FIG. 2.-Estimates of GFR from the slope clearance of ${ }^{51} \mathrm{Cr}-E D T A$ and creatinine clearances in a 14-year-old boy with Henoch-Schönlein nephritis. Note that the consistent downward trend of GFR is apparent from the slope clearance data but not from the creatinine clearances.

and a longer time may elapse before the falling plasma concentration curve can be described by a single exponential function. It is therefore necessary to take more blood samples in patients with oedema in order to be certain that the monoexponential part of the curve has been correctly identified. The method is not suitable for patients with large collections of fluids such as ascites or pleural effusions (Chantler, 1971).

Though the tracer is substantially equilibrated by 2 hours in the normal subject, complete equilibration probably takes much longer. The fraction not equilibrated by 2 hours, however, is so small that it cannot be detected in relation to a fast clearance, but in the presence of renal failure (GFR $15 \mathrm{ml} / \mathrm{min}$ per $1.73 \mathrm{~m}^{2} \mathrm{SA}$ ), the apparent clearance of this small fraction into the tissues becomes more important in relation to the renal clearance and accurate estimates of GFR require plasma sampling for up to 6 to 8 hours (Maisey, Ogg, and Cameron, 1969).

The reproducibility of replicate measurements of slope clearance in the same individual is evidently superior to the creatinine clearance (Dodge et al., 1967), and even the inulin clearance measured by standard techniques has a coefficient of variation of about 8\% (Davies and Shock, 1950). Slope clearance techniques using sodium ${ }^{125}$ I-diatrizoate have also been reported to have a reproducibility of $\pm 5 \%$ (Beeley and Kendall, 1971).

The slope clearance is especially suitable for monitoring the progress of patients with chronic renal disease; its superiority to the creatinine clearance is apparent in Fig. 2, in which the deterioration of GFR in a boy with Henoch-Schönlein nephritis can be discerned from the slope clearance data but not from the creatinine clearances. It requires a single intravenous injection, and two blood samples, and the laboratory work is simple, quick, and can be performed in any department with gamma-counting facilities. The radiation dose involved in a man with normal renal function is equivalent to that received daily from natural sources (Chantler et al., 1969). The amount of EDTA used in each test is about 1000 times less than the normal therapeutic dose of EDTA used in chelation therapy and in well over 300 measurements to date in all age groups we have witnessed no ill effects from the investigation.

We would like to thank Dr. N. Veall and Professor J. F. Soothill for valuable advice, and Mr. M. J. R. Healy for assistance with the statistical analyses. C.C. was in receipt of a Medical Research Council Clinical Fellowship. This study forms part of an M.D. Thesis recently submitted to the University of Cambridge by one of us (C.C.).

\section{REFERENCES}

Barratt, T. M., and Chantler, C. (1970). Obstructive uropathy in infants. Proceedings of the Royal Society of Medicine, 63, 1248.

Beeley, L., and Kendall, M. J. (1971). Effect of aspirin on renal clearance of ${ }^{125}$ I-diatrizoate. British Medical fournal, 1, 707.

Brien, T. G., O'Hagan, R., and Muldowney, F. P. (1969). Chromium-51-EDTA in the determination of glomerular filtration rate. Acta Radiologica [Therapy, Physics, Biology], 8, 523.

Bröchner-Mortensen, J., Giese, J., and Rossing, N. (1969). Renal inulin clearance versus total plasma clearance of ${ }^{51} \mathrm{Cr}$-EDTA. Scandinavian fournal of Clinical and Laboratory Investigation, 23, 301.

Chantler, C. (1971). M.D. Thesis submitted to the University of Cambridge.

Chantler, C., Garnett, E. S., Parsons, V., and Veall, N. (1969). Glomerular infiltration rate measurement in man by the single injection method using ${ }^{51} \mathrm{Cr}-\mathrm{EDTA}$. Clinical Science, 37, 169.

Davies, D. F., and Shock, N. W. (1950). The variability of measurement of inulin and diodrast tests of kidney function. Fournal of Clinical Investigation, 29, 491.

Dodge, W. F., Travis, L. B., and Daeschner, C. W. (1967). Comparison of endogenous creatinine clearance with inulin clearance. American fournal of Diseases of Children, 113, 683.

Doolan, P. D., Alpen, E. L., and Theil, G. B. (1962). A clinical appraisal of the plasma concentration and endogenous clearance of creatinine. American Fournal of Medicine, 32, 65.

Ekins, R. P., Nashat, F. S., Portal, R. W., and Sgherzi, A. M. (1966). The use of labelled vitamin $B_{12}$ in the measurement of glomerular filtration rate. Fournal of Physiology, 186, 347.

Kim, K. E., Onesti, G., Ramirez, O., Brest, A. N., and Swartz, C. (1969). Creatinine clearance in renal disease: a reappraisal. British Medical fournal, 4, 11. 
Lavender, S., Hilton, P. J., and Jones, N. F. (1969). The measurement of glomerular filtration-rate in renal disease. Lancet, 2 , 1216.

Maisey, M. N., Ogg, C. S., and Cameron, J. S. (1969). Measuring glomerular filtration-rate. (Letter.) Lancet, 1, 733.

Smith, H. W. (1951). The Kidney: Structure and Function in Health and Disease, p. 57. Oxford University Press, New York.

Stamp, T. C. B., Stacey, T. E., and Rose, G. A. (1970). Comparison of glomerular filtration rate measurements using inulin, 51CrEDTA, and a phosphate infusion technique. Clinica Chimica Acta, 30, 351.
Stoten, A. (1968). A micromethod for creatinine using resin to remove interfering substances. Fournal of Medical Laboratory Technology, 25, 240.

Truniger, B., Donath, A., and Kappeler, M. (1968). Simplified clearance techniques: the single injection method and its modifications. Helvetica Medica Acta, 34, 116.

Correspondence to Dr. T. M. Barratt, Department of Immunology, Institute of Child Health, London W.C.1. 